\title{
BMJ Open Prevalence of cleft lip and/or cleft palate in Guangdong province, China, 2015-2018: a spatio-temporal descriptive analysis
}

\author{
Yingxian Zhu, ${ }^{1}$ Huazhang Miao, ${ }^{1}$ Qinghui Zeng, ${ }^{2}$ Bing Li, ${ }^{1}$ Degang Wang, ${ }^{3}$ \\ Xiaolin Yu, ${ }^{2}$ Haisheng Wu, ${ }^{2}$ Yuliang Chen, ${ }^{2} \mathrm{Pi}$ Guo, ${ }^{2}$ Fenghua Liu (D) ${ }^{1}$
}

To cite: Zhu Y, Miao H, Zeng Q, et al. Prevalence of cleft lip and/ or cleft palate in Guangdong province, China,

2015-2018: a spatio-temporal descriptive analysis. BMJ Open 2021;11:e046430. doi:10.1136/ bmjopen-2020-046430

- Prepublication history for this paper is available online. To view these files, please visit the journal online (http://dx.doi org/10.1136/bmjopen-2020046430).

$\mathrm{YZ}, \mathrm{HM}, \mathrm{QZ}$ and BL contributed equally.

$\mathrm{YZ}, \mathrm{HM}, \mathrm{QZ}$ and $\mathrm{BL}$ are joint first authors.

Received 02 November 2020 Accepted 17 July 2021

Check for updates

(c) Author(s) (or their employer(s)) 2021. Re-use permitted under CC BY-NC. No commercial re-use. See rights and permissions. Published by BMJ.

${ }^{1}$ Guangdong Women and Children Hospital, Guangzhou, Guangdong, China

${ }^{2}$ Department of Preventive Medicine, Shantou University Medical College, Shantou, China

${ }^{3}$ Boai Hospital of Zhongshan,

Zhongshan, China

Correspondence to

Fenghua Liu;

liushine2020@163.com and

Pi Guo;

pguo@stu.edu.cn

\section{ABSTRACT}

Objectives This study aimed to investigate the temporal and spatial characteristics of cleft lip and/or palate based on a large-scale birth defect monitoring database.

Methods Data on perinatal infants and children with cleft lip and/or palate defects from 1 January 2015 to 31 December 2018 in Guangdong province of China were collected. The variables including the demographic data, basic family information (address, education level, etc.), the infant's birth weight, gender and other basic parameters were collected and analysed.

Results During the study period, the prevalence of cleft lip and/or palate was 7.55 per 10000 perinatal infants. The prevalence of cleft lip, cleft palate and cleft lip and palate were 2.34/10 000, 2.22/10 000 and 2.98/10 000, respectively. The prevalence of cleft lip and/or palate showed a pronounced downward trend, reducing from $8.47 / 10000$ in 2015 to $6.51 / 10000$ in 2018 . We observed spatial heterogeneity of prevalence of cleft lip and/or palate across the study period in Guangdong. In the Pearl River Delta region, the overall prevalence of cleft lip and/ or palate was $7.31 / 10000$, while the figure $(7.86 / 10000)$ was slightly higher in the non-Pearl River Delta region $(p<0.05)$. Concerning infant gender, the prevalence was in general higher in boys than girls $(p<0.05)$. In addition, the higher prevalence was more common in mothers older than 35 years old. For the birth season, infants born in spring tended to have a higher prevalence than those born in other seasons, regardless of the prevalence of cleft lip and palate calculated separately or jointly $(p<0.05)$. The majority of newborns with cleft lip and palate were accompanied by other birth defects.

Conclusion This study contributes a better understanding of the characteristics of spatio-temporal trends for birth defects of cleft lip and/or palate in south China.

\section{INTRODUCTION}

Cleft lip and/or cleft palate are congenital abnormalities, which caused by the disruption of teratogenic threats in the early stage of embryonic development and the cracking of the lips or palate. ${ }^{1}$ Cleft lip and/or cleft palate can occur synchronously or asynchronously and can be mild or severe with or
Strengths and limitations of this study

- This study is a descriptive analysis focused on temporal and spatial characteristics of cleft lip and/or palate and revealed the current situation of adverse birth outcomes in Guangdong, south China.

- Multiple adverse pregnancy outcomes including cleft lip, cleft palate and cleft lip and palate have been investigated and compared in terms of their temporal trend and spatial distribution.

- This study based on a cohort of nearly 7.1 million live births contributed a better understanding of spatio-temporal distribution characteristics of the birth defects in the study area.

- As a descriptive analysis, this study was unable to identify the causal relationship between spatiotemporal factors and adverse pregnancy outcomes.

- As we only have 4 years of data that is limited to determine a trend, these trends of birth defect need to be taken with caution.

without alveolar clefts. The disease can be divided into non-syndrome and syndrome types. ${ }^{2}$ Non-syndromic type accounts for more than $70 \%$ of facial congenital malformations. ${ }^{3}$ Non-syndromic type can also be divided into cleft lip, cleft palate and cleft lip and palate, which does not include other systemic deformities and syndromes. Syndrome type accounts for less than $30 \%$ of the entire facial deformity. In addition to cleft lip and/or palate, syndrome type has deformities of other tissues and organs in the body, which are more than 300 types. Cleft lip and/ or palate could bring a huge health burden to patients and families, and have a negative impact on patients' mental health and quality of life. ${ }^{4}$ The disease is usually accompanied by various complications, which mainly affect voice and face. ${ }^{5}$ A previous study ${ }^{6}$ showed that adults with oral-facial clefts have a negative sense of social belonging and adaptation, compared with healthy adults. 
As for the international distribution of cleft lip and palate, the prevalence of cleft lip and palate is declining globally. ${ }^{7}$ In many other regions, data on cleft lip and palate cases are of poor or incomplete quality, often lacking information on important variables such as gender and severity of morphological abnormalities, the published data on the prevalence of cleft lip and/or cleft palate from different parts of the world are quite different. ${ }^{8}$ A previous study revealed that the African population had the lowest incidence of the disease, which is about $0.4 / 1000$; in India, the average prevalence index of this disease was $0.398 / 1000$ from 2007 to $2011 .^{9}$ Europe's incidence is about 1/1000; Asia and South Americas have relatively a high incidence of about $2 / 1000 .{ }^{10} \mathrm{Cleft}$ lip and/or palate have the highest rates at birth in Asian (especially in China and Japan), ${ }^{3}$ and China is one of the regions with high incidence of about $1.663 / 1000 .^{9}$

Guangdong province is located in southern China, with 21 cities and a large population. Its Gross Domestic Product (GDP) ranks first in the country, however, the economic development is quite unbalanced among cities in the province. In Guangdong province, the Pearl River Delta regions are economically developed regions with a GDP accounting for $80 \%$ of the province, and hence have a better distribution of health resources. However, the non-Pearl River Delta regions are mainly economically undeveloped areas, and so as the distribution of health resources. In order to improve the quality of the birth health, understand the status and tendency of birth defects during perinatal period, and then provide scientific basic evidence for further intervention, Guangdong province has launched a birth defects surveillance programme based on hospitals since the end of 1980s by government, and then the monitoring hospitals had been expanded to all hospitals with midwifery services cross over province since October 2014. ${ }^{11}$ Guangdong province stipulates that perinatal infants born in medical institutions must routinely monitor 23 types of congenital defects including cleft lip and palate. A 'Registration Card for Birth Defect' should be reported through the Guangdong Province Maternal and Child Health Information Platform when a birth defect of perinatal infant is diagnosed in any monitoring hospital. Based on the monitoring data of perinatal and birth defects in Guangdong, this study intended to investigate the epidemiological status and characteristics of temporal and spatial distribution for cleft lip and palate in Guangdong. The results of this study could provide a relevant basis for the ongoing prevention and control strategy of cleft lip and palate.

\section{MATERIALS AND METHODS}

\section{Patient and public involvement}

A total of 7134693 perinatal infants in all midwifery institutions in Guangdong province from 1 January 2015 to 31 December 2018 were reported and included. Among them, we identified a total of 9353 children with cleft

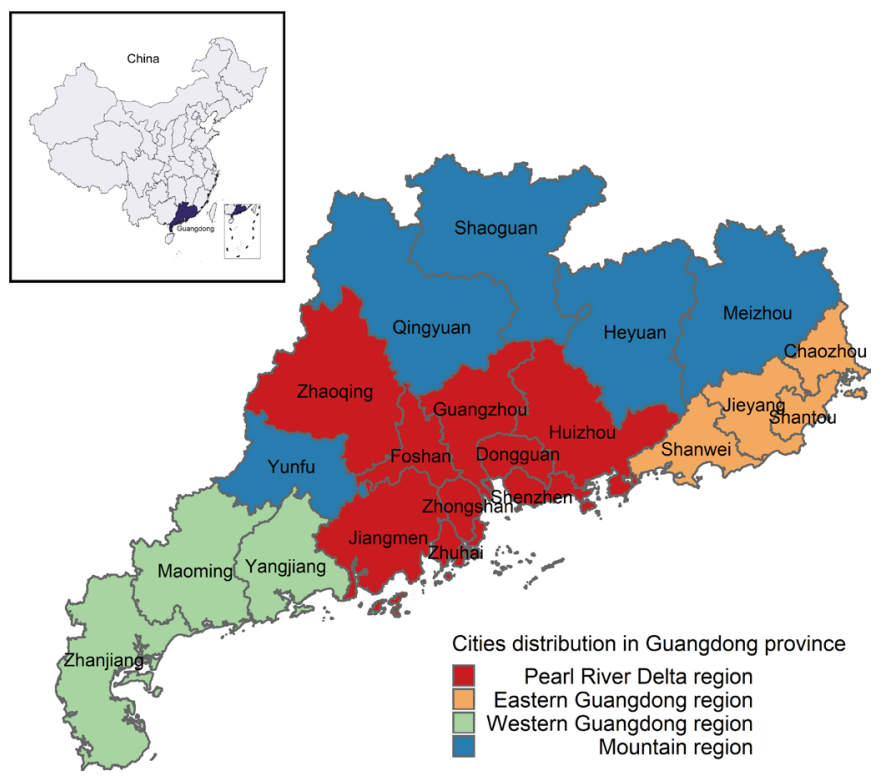

Figure 1 Geographical locations of the study area. Guangdong province is located in south China. This study included all 21 cities in Guangdong province, which are Guangzhou, Shenzhen, Foshan, Dongguan, Zhuhai, Zhongshan, Zhaoqing, Huizhou, Jiangmen, Chaozhou, Shantou, Jieyang, Meizhou, Shanwei, Shaoguan, Heyuan, Qingyuan, Yunfu, Yangjiang, Maoming and Zhanjiang.

lip and/or palate defects, including live births, stillbirths and early neonatal deaths. We excluded newborns whose gestational age less than 28 weeks and more than 1 week after delivery $(n=3892)$ and 77 cases absence of gestational weeks. After that, there were 5384 perinatal infants with defects of cleft lip and/or palate included as the study subjects. There were some missing value in the variables, including maternal gestational age $(n=41)$, race $(n=20)$, residential areas $(n=285)$, infants sex $(n=24)$, multiple births $(n=23)$, birth weight $(n=400)$, time of diagnosis $(n=489)$, pregnancy outcome $(n=187)$, per capita income of household $(n=572)$, parity $(n=177)$ and maternal education level $(\mathrm{n}=964)$.

\section{Study site}

Figure 1 shows the location of Guangdong province and the regional distribution of 21 cities. Guangdong province, which located in south China, is the most economically developed province in the region. The 21 cities can be divided into four regions, namely the Pearl River Delta region, the East Guangdong region, the West Guangdong region and the Mountainous region. There are nine cities in the Pearl River Delta region, including Guangzhou, Shenzhen, Foshan, Dongguan, Zhuhai, Zhongshan, Jiangmen, Huizhou and Zhaoqing. The East Guangdong region contains four cities, including Shantou, Chaozhou, Jieyang and Shanwei. The West Guangdong region includes Yangjiang and Maoming, Zhanjiang and other three cities. And the cities of Shaoguan, Qingyuan, Heyuan, Meizhou and Yunfu are considered as the Mountainous region. The Pearl River Delta region is the largest plain area in Guangdong province, and also the most 
densely populated and economically developed area. Compared with the Pearl River Delta region, the other three regions are economically underdeveloped areas in the province. In particular, there are insufficient medical and health resources and uneven distribution in the Mountainous region of Guangdong province. ${ }^{12} 13$

\section{Data sources}

We extracted data from the Guangdong Province Maternal and Child Health Information Platform, which including registration cards and quarterly reports for infants with birth defects uploaded by more than 1900 midwifery institutions. The content of the Registration Card for Birth Defects includes basic prenatal conditions (age, education, date of last menstrual period, gestational week, pregnancy, parity, etc.) and postpartum conditions (delivery methods, infant gender, weight, height, etc.). The contents of the quarterly report include the number of perinatal babies per month, the number of perinatal babies by gender, the number of birth defects and deaths, age of pregnant mothers and the area of residence. To ensure the quality of monitoring data, the registration card and the quarterly report need to go through multilevel review by institutional, county, district, city and provincial levels. Once the data are rejected at any level, the medical workers of the institution must verify and correct the data based on clinical information.

\section{Diagnosis of cleft lip and palate}

Cases of cleft lip and palate were diagnosed by medical workers of midwifery institutions in accordance with a unified standard of the 'China Birth Defect Programme', and relevant information was filled in the registration card for birth defects. Medical workers can choose methods of auxiliary examinations including ultrasound and autopsy based on symptoms, signs and medical history to detect the cases of cleft lip and palate. Medical workers must indicate the diagnosis method when they fill out the Registration Card for Birth Defects. The diagnostic criteria meet the following conditions: (1) cleft lip (ICD 10: Q35.0-Q35.9): partial or complete split of one or both sides of the upper lip at birth, including recessive split; (2) cleft palate (ICD 10: Q36.0-Q36.9): at birth, partially or completely split of the uvula and soft palate include or exclude one or both sides of the hard palate; (3) cleft lip and palate (ICD 10: Q37.0-Q37.9): both cleft lip and/or cleft palate at birth.

\section{Statistical analysis}

The prevalence of different disease types of cleft lip and/ or palate was calculated according to the urban and rural areas, the Pearl River Delta areas and the non-Pearl River Delta areas, different age groups of pregnant mothers and different birth seasons. Descriptive statistics were used to show the basic characteristics of cleft lip and/or palate children and their pregnant mothers. The characteristics including the mother's ethnicity, parity, conception season, income level, education level and the birth weight, gender, single or multiple births, whether there are other birth defects and prognosis were investigated. After we calculated the prevalence of cleft lip and/or palate based on the characteristics of the newborn and their mother, we used the $\chi^{2}$ test to compare the prevalence, if necessary, the cohran-Armitage test was used in search of trends, for example, a trend in the years. Also, we compared each age category to the 25-29 age category, and obtained a separate adjusted $\mathrm{p}$ value for each category $(<24,30-34$ and $\geq 35)$ versus 25-29 using the adjustment method of Benjamini and Hochberg. The similar analysis approach was conducted to compare each season of birth category to the spring category and obtained a separate adjusted $p$ value for each category (summer, autumn and winter) versus spring. According to whether other birth defects were combined, we analysed the prognosis of children with different types of cleft lip and palate, including live birth, stillbirth and death within 7 days after birth. The $p$ values derived from all statistical analyses were then compared with the adopted significance level of 0.05. A map was used to depict the location of Guangdong province in China and the geographical distribution of the four regions in Guangdong province (the Pearl River Delta regions, the East Guangdong, the West Guangdong and the Mountain regions). We used a dot-line diagram to demonstrate the annual prevalence trend of cleft lip and/or palate in Guangdong. Finally, we used maps to demonstrate the annual prevalence trend of cleft lip and/ or palate in all cities of Guangdong. All statistical analyses were performed within the R V.3.62 software.

\section{RESULTS}

Figure 2 shows that the prevalence of cleft lip and/or palate was $7.55 / 10000(95 \% \mathrm{CI}=7.35 / 10000$ to $7.75 / 10$ $000)$. During the study period, the prevalence of cleft lip and/or palate showed a pronounced downward trend based on the cohran-Armitage test, reducing from $8.47 / 10000(95 \% \mathrm{CI}=8.04 / 10000$ to $8.93 / 10000)$ in 2015 to $6.51 / 10000(95 \% \mathrm{CI}=6.13 / 10000$ to $6.91 / 10000)$ in 2018 ( $\mathrm{p}<0.05$, cohran-Armitage test). The annual prevalence of cleft lip $(2.68 / 10000,95 \% \mathrm{CI}=2.43 / 10000$ to $2.94 / 10000)$, cleft palate $(2.45 / 10000,95 \% \mathrm{CI}=2.22 / 10$

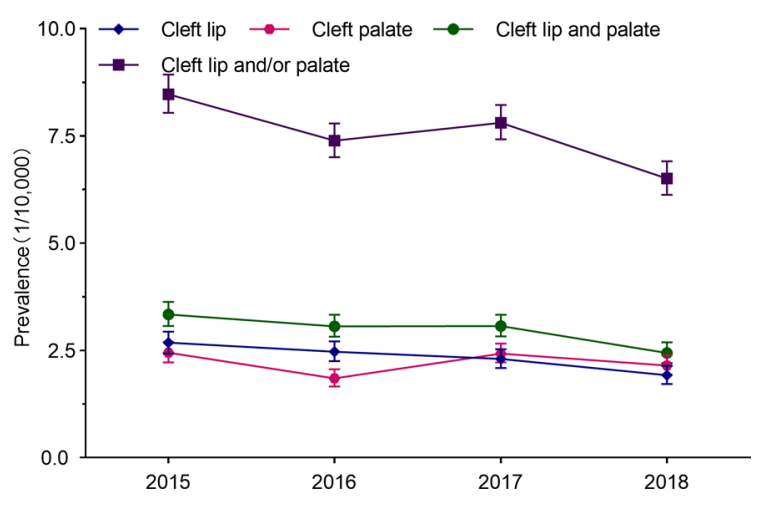

Figure 2 Prevalence of cleft lip and/or palate (per 10000 perinatal infants) in Guangdong province, China, 2015-2018. 


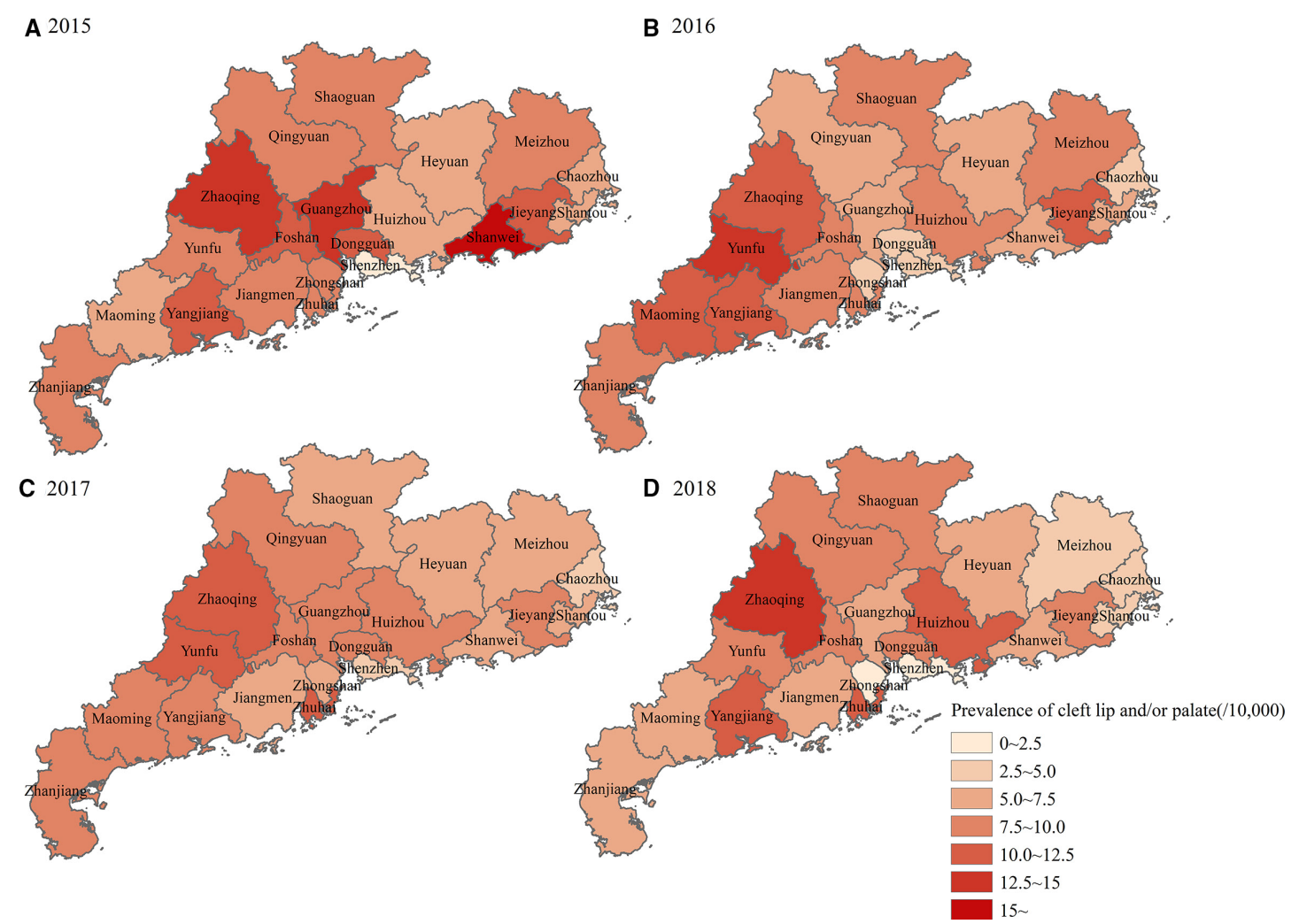

Figure 3 Spatial distributions of the prevalence of cleft lip and/or palate in Guangdong Province, China, 2015-2018. Spatial distributions of cleft lip and/or palate prevalence in (A) 2015, (B) 2016, (C) 2017 and (D) 2018.

000 to $2.70 / 10000)$ and cleft lip and palate $(3.34 / 10$ $000,95 \% \mathrm{CI}=3.07 / 10000$ to $3.63 / 10000)$ were highest in 2015. From 2015 to 2018, the annual prevalence was relatively stable for cleft lip or cleft palate alone, with a slight decline across the years. When considering the infants born with cleft lip and palate, the annual prevalence decreased from 3.34/10 $000(95 \% \mathrm{CI}=3.07 / 10000$ to $3.63 / 10000)$ in 2015 to $2.44 / 10000$ (95\% CI=2.21/10 000 to $2.69 / 10000)$ in 2018 ( $\mathrm{p}<0.05$, cohran-Armitage test).

Figure 3 shows the spatial distribution characteristics of the prevalence of cleft lip and/or palate in all 21 cities in Guangdong province, China, from 2015 to 2018. In 2015, Shanwei city had the highest prevalence $(21.68 / 10000)$ of cleft lip and/or palate, while Shenzhen city had the lowest figure $(0.65 / 10000)$. In 2016 , the highest prevalence $(12.92 / 10000)$ occurred in Yunfu city, while the prevalence $(2.64 / 10$ 000) was lowest in Dongguan city. In the last 2 years of 2017 and 2018, Zhaoqing city had the highest prevalence of cleft lip and/or palate, with the figure of 12.06/10 000 and 13.30/10 000, respectively. However, in 2017 and 2018, the lowest prevalence occurred in Shenzhen (2.92/10 000) and Zhongshan city $(1.64 / 10000)$, respectively. Spatial heterogeneity of prevalence of cleft lip and/or palate across the study period in Guangdong province was observed.

Table 1 shows the prevalence of cleft lip and/or palate in different subgroups. When considering the strata of residential areas of infants, the prevalence of cleft palate alone for urban residents was in general higher than that for rural residents $(2.80 / 10000$ vs $1.59 / 10000, \mathrm{p}<0.05)$. However, the prevalence of cleft lip and palate for rural infants was higher than that for urban infants $(3.25 / 10$ 000 vs $2.32 / 10$ 000). In the Pearl River Delta region, the overall prevalence of cleft lip and/or palate was 7.31/10 000 , while the figure $(7.86 / 10000)$ was slightly higher in the non-Pearl River Delta region $(p<0.05)$. Similarly, the prevalence $(2.45 / 10000)$ of cleft lip and palate in the non-Pearl River Delta region was higher than that $(2.26 / 10000)$ in the Pearl River Delta region $(p<0.05)$. On the contrary, as for cleft palate alone, the prevalence $(2.63 / 10000)$ in the Pearl River Delta region was slightly higher than that $(1.68 / 10000)$ in the non-Pearl River Delta region $(\mathrm{p}<0.05)$. In general, our results indicated an increased risk in young women and in older women $(p<0.05)$. Furthermore, based on the comparison of each age category to the 25-29 age category, the prevalence was much higher among babies born by mothers older than 35 years of age in cleft lip and/or palate newborns (adjusted $\mathrm{p}<0.05$ ). Besides, except for cleft palate, the prevalence of cleft lip and/or palate in newborns born by mothers under 24 years old was significantly higher than reference category of mothers aged 25-29 age old (adjusted $\mathrm{p}<0.05$ ). For birth season, we observed that infants born in spring tended to have an increased risk of these defects than those born in other seasons, regardless of the prevalence of cleft lip and palate calculated separately or jointly $(p<0.05)$, and found that the prevalence of cleft lip and palate and the prevalence of cleft lip and/ or palate were significantly associated with the birth in 


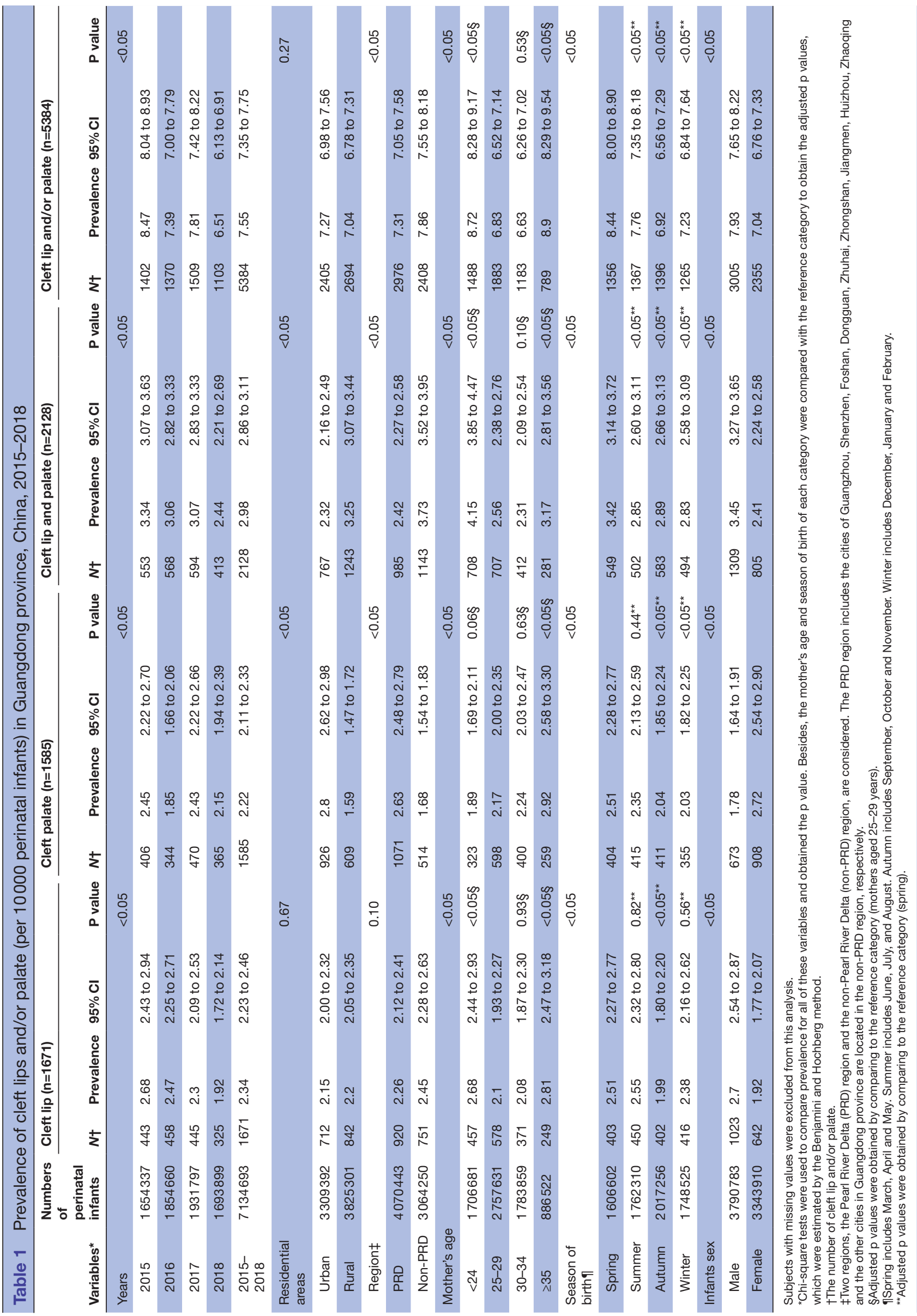


spring (adjusted $\mathrm{p}<0.05$ ) by comparing each season of birth category to the spring category. Concerning infant gender, the prevalence of the disease was in general higher in boys than girls. For example, the overall prevalence of cleft lip and/or palate in boys was 7.93/10 000, while the figure in girls was 7.04/10 $000(\mathrm{p}<0.05)$.

Table 2 shows the percentage of cleft lip and/or palate across different subgroups stratified by characteristics of mothers and infants. The percentage of cleft lip and/ or cleft palate was larger among women who have given birth before $(54.1 \%)$ than women who have not given birth before $(45.9 \%)$. In particular, we observed that the percentage of cleft lip and/or palate perinatal from highincome families (per capita income of household each year greater than or equal to $8000 ¥$ ) was in general larger than in low-income families (per capita income of household each year less than 4000¥ or between 40000 and $8000 ¥)$. We also found that infants born by mothers with an education level of middle school or less accounted for the majority of cleft lip and/or palate perinatal (63.3\%). Also, the relatively large number of cleft lip and/or palate cases was observed in perinatal infants born by mothers with gestational age less than 28 weeks compared with the other two groups of gestational age. Among cleft lip and/ or palate perinatal, infants with a birth weight of 2500$4000 \mathrm{~g}$ were the majority. Among perinatal infants with cleft lip and palate, boy infants $(61.6 \%)$ were in general more common than girls $(37.9 \%)$. The percentage of cleft lip and palate was higher in mothers with multiple births than those with single birth. Also, cleft lip and palate infants were often accompanied by other defective diseases. During the study period, most of the cleft lip and palate infants were live births $(75.4 \%)$.

Table 3 shows the pregnancy outcome of cleft lip and/ or palate perinatal infants with other defective diseases or not. For example, most of the live births with cleft lip and/or palate were accompanied by other defective diseases, accounting for $78.2 \%$. Similar results were observed among stillbirths or infants dead within 7 days, suggesting that the majority of newborns with cleft lip and palate were accompanied by other birth defects.

\section{DISCUSSION}

In some countries, accurate demographic data and related cases are difficult to obtain partly due to the fact that the quality of the data was often poor. ${ }^{14}$ Most of the previous relevant studies mainly focused on the comparison of the prevalence of the disease. However, we found that there is a lack of relevant studies describing the spatio-temporal characteristics of the disease. We used a reliable data platform for birth defects surveillance that offers accurate and high-quality data to investigate the issue. Our research focused on the perinatal infants who were delivered in all midwifery institutions in the region from 1 January 2015 to 31 December 2018, and described the spatio-temporal and epidemiological characteristics of cleft lip and/or palate in Guangdong province.
Cleft lip with or without cleft palate is the most prevalent congenital craniofacial defect, it is caused by the embryonic developmental disorder of the soft and hard tissues around the cavity and face. ${ }^{15}$ It is a heterogeneous group of disorders affecting the structure of the face and oral cavity that has been divided into three general categories: cleft lip, cleft lip and palate and cleft palate. ${ }^{16-18} \mathrm{Cleft}$ lip and palate may be the result of Mendelian syndrome, it may be a phenotype caused by chromosomal abnormalities or it may be the result of prenatal exposure to certain teratogens. ${ }^{19}$ The patient's ability to swallow and speak will be severely restricted, as well as insufficient oral space, breathing difficulties and self-esteem problems due to facial appearance. ${ }^{20}$ Besides, the prevalence of cleft lip and/or palate was 7.55/10 000. Some previous studies ${ }^{14}$ revealed that the prevalence of cleft lip and/or palate was approximately one patient per 1700 newborns, with East Asia and the Pacific considered having the highest prevalence. The prevalence of the disease in newborns in South Asia and North Africa was 12.8/10 000 and 12.2/10 000, respectively. ${ }^{821}$ A recent report published by the International Clearinghouse for Birth Defects Surveillance and Research revealed that the average prevalence of the disease was 21.67/10 000 in Japan from 2007 to $2011 .^{9}$ In 2016 , the prevalence $(20.2 / 10000)$ of the disease had declined slightly in Japan. ${ }^{22}$ The prevalence of the disease in South Korea was 11.09/10 000. ${ }^{22}$ From 2008 to 2012, the Netherlands had 330 cases of the disease, with a prevalence of $15 / 10000 .{ }^{23}$ An investigation analysed the cases of cleft lip and palate from 45 hospitals in Bogata and Cali from 2001 to 2015, and revealed that the prevalence was $11.8 / 10000 .^{24}$ The prevalence of the disease in the regions mentioned above was in general higher than that of our present study. Since our study only focused on the perinatal infants, this may result in relatively low estimates of the prevalence of these defects. However, we also need to note that the prevalence in some areas was much lower than the figure of our local prevalence. For example, an analysis of cleft lip and palate in Colombia showed that the prevalence was 3.27 per 10000 inhabitants from 2009 to $2017 .^{25}$ Also, the prevalence of the disease in Brazil was about 5.2/10 000. ${ }^{26}$ Compared with some cities in our country, we found that the prevalence of cleft lip and/ or palate in Guangdong province was lower than that in Beijing $(18.9 / 10000)^{9}$ and Gansu province (13.48/10 $000){ }^{27}$

The results of our present study revealed the epidemiological characteristics and spatio-temporal trends of cleft lip and/or palate in Guangdong, the most economically developed province in South China. The time trends in the prevalence of cleft lip and/or palate may reflect the changes in risk factors and pathogenesis related to the disease. Our research shows that the prevalence of cleft lip only and cleft lip and palate shows a downward trend from 2015 to 2018, while the prevalence of cleft palate is relatively stable. Over time, the prevalence of all types of clefts seems to be decreasing. ${ }^{28} 29$ In a study focused on the time trend of cleft lip and/or palate, the 


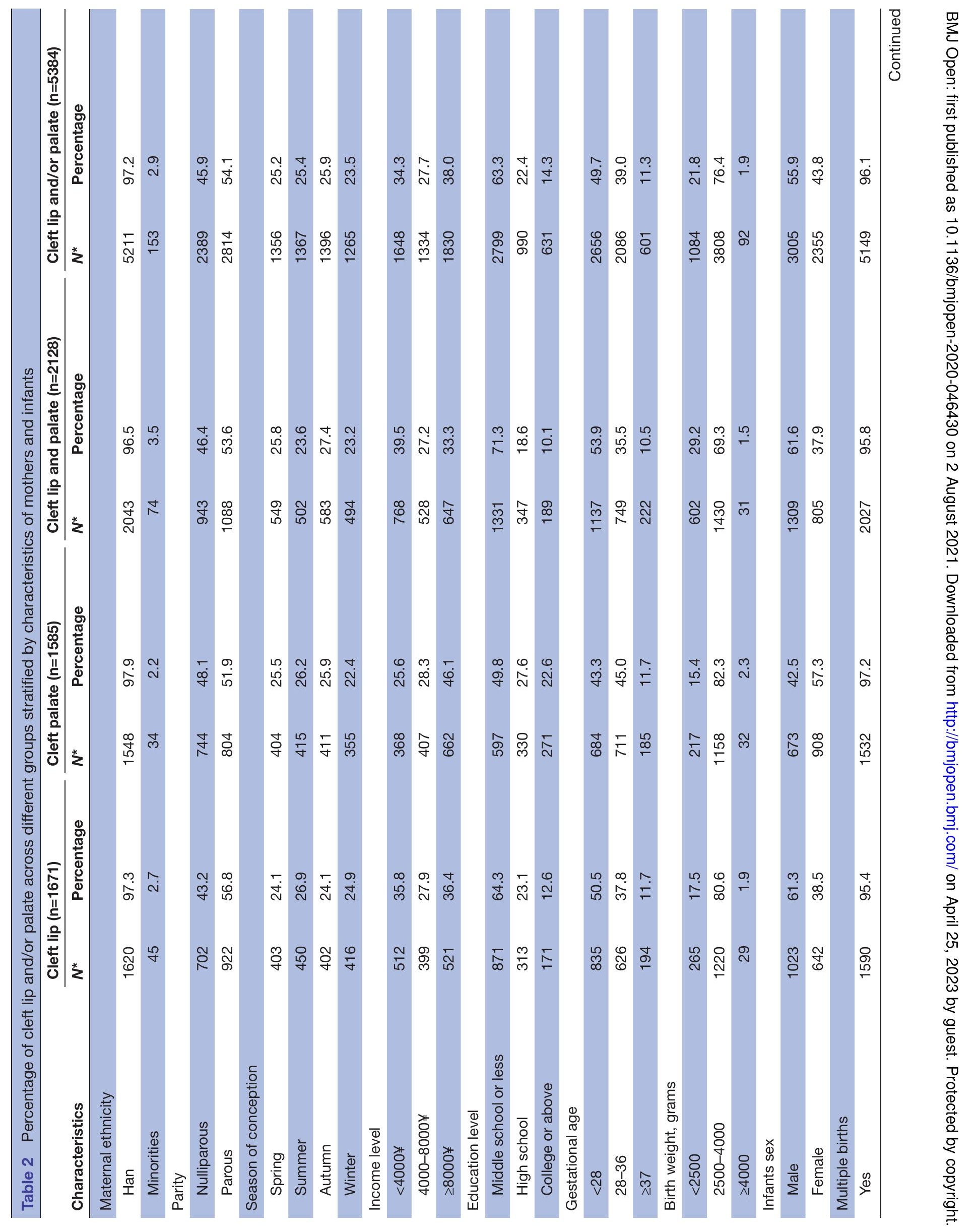




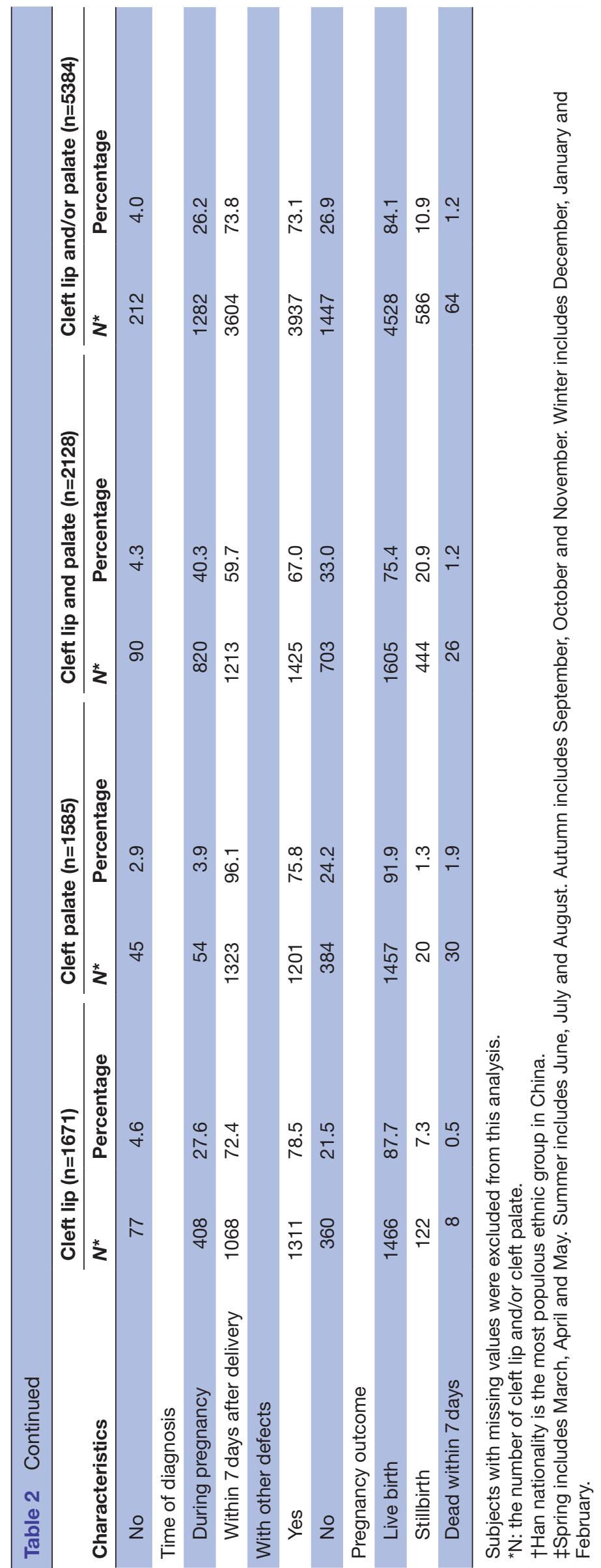

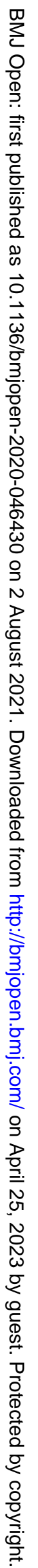


prevalence of cleft lip only and cleft lip and palate showed a decreasing trend, ${ }^{30}$ which was consistent with our result. But a study in Brazil from 2000 to 2013 showed that the prevalence of cleft lip and/or palate in the region showed an upward trend, especially in poor areas, this may be the result of imbalanced health resources. ${ }^{31}$ In China, an epidemiological study revealed that the birth defects had a clear increasing trend, based on 2011-2015 birth defect monitoring data in Guangxi province, China.$^{32}$ Research showed that the prevalence had a rising trend in recent years in Gansu province. ${ }^{27}$ We speculate that the differences between these studies and our results may be due to the imbalance of public health resources and that these research sites are located in economically underdeveloped areas. ${ }^{31}$

For spatial distributions of the prevalence, we observed spatial heterogeneity of prevalence of cleft lip and/or palate across the study period in Guangdong province. For the prevalence of the disease in the world, previous studies showed that the figure was quite different, ${ }^{8}$ which indicated that the distribution of the disease was unbalanced and there existed spatial heterogeneity globally. ${ }^{28}$ For example, the prevalence was relatively high in East Asia and the pacific compared with other regions in the world. ${ }^{25}$ In addition, the prevalence of the disease was unevenly distributed in different regions and/or ethnic groups in a single country, such as the heterogeneity of different regions in Georgia. ${ }^{28}$ According to the WHO, the prevalence of birth defects in the Netherlands varied greatly. ${ }^{23}$ Similarly, a study revealed that there were differences in the time trend of the prevalence among 31 different geographic regions in Brazil from 1975 to $1994 .{ }^{31}$ In our study, the prevalence of cleft lip and palate in urban areas is higher than that in rural areas. During 2005-2014, the prevalence in urban areas in Hunan province of China was higher than that in rural areas, ${ }^{33}$ which was consistent with our findings on spatial heterogeneity in the prevalence of these defects. Furthermore, it is necessary to investigate whether there are no clusters with a defect frequency atypical for the analysed area. Then, we can compare these regions with those of lower frequency in terms of age, income, education, and other factors.

We observed a higher prevalence of cleft lip and/ or palate in perinatal infants for older mothers. As the parents get older, their offspring with cleft lip and palate were at a higher risk of more severe disease. ${ }^{34}$ Moreover, according to our research results, we observed that the prevalence of male infants with cleft lip alone or cleft lip and palate was higher than that of female infants $(p<0.05)$, while the prevalence of female infants with cleft palate alone was higher than that of male infants $(p<0.05)$. According to a previous study, gender differences in the incidence among cleft subgroups were observed, with the higher incidence of cleft palate, cleft lip and palate, as well as cleft lip and/or palate occurred in male infants except for cleft palate, ${ }^{35}$ which are similar to the results of our study. This similar result supports our findings. 
Overall, the higher prevalence of the disease occurred in male infants. ${ }^{19} 36{ }^{37}$ The higher prevalence among boy infants may be partly due to higher sensitivity to environmental pressure as well as gene mutations. ${ }^{35}$ For gender disparity, our results were also supported by some epidemiological and genetic studies. For example, several studies showed that cleft lip and cleft lip and palate were more common in male infants, and cleft palate was more common in female infants. ${ }^{38-40}$ Our results indicate that male infants with older parents were at a higher risk of cleft lip and palate. In this study, the majority of perinatal infants with cleft lip and palate were complicated by other defects, which may affect the survival rate of the infant, and further research is needed.

This study does have some limitations. First, this study is only a descriptive analysis that exploring the spatiotemporal distribution of cleft lip and/or palate in the region. It does not provide a clear causal relationship between the disease and those spatio-temporal factors. Thus, an in-depth analysis to identify the subgroups at a higher risk of the cleft lip only and cleft lip and palate based on a multivariate approach should be performed in subsequent studies. Second, although our study revealed the spatial distributions and temporal trends in the prevalence of cleft lip and/or palate, we did not consider some potential factors in our study, because these factors may have an impact on the spatio-temporal distribution of the disease. Third, as we only have 4 years of data that is limited to determine a trend, these trends of defect need to be taken with caution. Fourth, cleft lip with or without cleft palate can present as an isolated malformation or a syndromic form of malformation. The discovery of corresponding etiologic factors is important. However, this present study did not differentiate isolated from syndromic forms due to the limitation of data. When more detailed data are available, this issue should be examined in our future studies. Furthermore, the different methods of data collection may have a potential impact on the research results. ${ }^{8}$

This present study is one of a few studies including a large number of perinatal infants to describe the spatiotemporal characteristics of cleft lip and/or palate in south China. The findings of this study could help to understand the epidemiological characteristics of the diseases and provide reliable descriptive material for the subsequent research of the disease.

\section{CONCLUSION}

Overall, in Guangdong province, the prevalence of cleft lip and/or palate gradually decreased during the study period from 2015 to 2018 . The spatial heterogeneity in the prevalence of cleft lip and palate was observed. Our results indicated that male infants are a risk group, and separately the babies born by mothers with older age have an increased risk of the disease. Most perinatal babies with cleft lip and palate tended to have other defects.
Contributors YZ, HM, QZ, BL, PG and FL conceived the study. YZ, HM, QZ, DW, $\mathrm{PG}$ and $\mathrm{FL}$ conducted the initial literature searches. YZ, HM, and QZ completed the initial drafts of the manuscript. YZ, HM, QZ, PG and FL revised the manuscript. YZ, HM, QZ, BL, PG and FL reviewed the statistical methods. HM, QZ, XY, HW and $Y C$ performed the statistical analysis. All authors read and approved the final manuscript.

Funding This work was supported by the major research plan of National Natural Science Foundation of China (no. 2018YFC1002604). The funder had no role in study design, data collection and analysis, decision to publish or preparation of the manuscript.

Map disclaimer The inclusion of any map (including the depiction of any boundaries therein), or of any geographic or locational reference, does not imply the expression of any opinion whatsoever on the part of BMJ concerning the legal status of any country, territory, jurisdiction or area or of its authorities. Any such expression remains solely that of the relevant source and is not endorsed by BMJ. Maps are provided without any warranty of any kind, either express or implied.

Competing interests None declared.

Patient and public involvement Patients and/or the public were not involved in the design, or conduct, or reporting or dissemination plans of this research.

Patient consent for publication Not required.

Ethics approval The study was approved by the Human Ethics Committee of Guangdong Women and Children Hospital (no. 201801023), and in accordance with the ethical standards of the 1964 Helsinki declaration and its later amendments.

Provenance and peer review Not commissioned; externally peer reviewed. Data availability statement Data are available upon reasonable request.

Open access This is an open access article distributed in accordance with the Creative Commons Attribution Non Commercial (CC BY-NC 4.0) license, which permits others to distribute, remix, adapt, build upon this work non-commercially, and license their derivative works on different terms, provided the original work is properly cited, appropriate credit is given, any changes made indicated, and the use is non-commercial. See: http://creativecommons.org/licenses/by-nc/4.0/.

ORCID iD

Fenghua Liu http://orcid.org/0000-0002-2376-7111

\section{REFERENCES}

1 McLeod NMH, Urioste MLA, Saeed NR. Birth prevalence of cleft lip and palate in Sucre, Bolivia. Cleft Palate Craniofac J 2004;41:195-8.

2 Allori AC, Mulliken JB, Meara JG, et al. Classification of cleft lip/ palate: then and now. Cleft Palate Craniofac J 2017;54:175-88.

3 Yu Y, Zuo X, He M, et al. Genome-wide analyses of non-syndromic cleft lip with palate identify 14 novel loci and genetic heterogeneity. Nat Commun 2017;8:14364.

4 Wehby GL, Cassell $\mathrm{CH}$. The impact of orofacial clefts on quality of life and healthcare use and costs. Oral Dis 2010;16:3-10.

5 Suleiman AM, Hamzah ST, Abusalab MA, et al. Prevalence of cleft lip and palate in a hospital-based population in the Sudan. Int $J$ Paediatr Dent 2005;15:185-9.

6 Berk NW, Cooper ME, Liu YE, et al. Social anxiety in Chinese adults with oral-facial clefts. Cleft Palate Craniofac J 2001;38:126-33.

7 Zhou Y, Mao X, Zhou H. Epidemiology of birth defects based on a birth defect surveillance system in southern Jiangsu, China, 2014-2018, 2020: 1-7.

8 Antoszewski B, Fijałkowska M. Prevalence of cleft lip and/or palate in children from Lodz between years 1981-2010. Congenit Anom 2016;56:60-4.

9 Yang Y, Liu H, Ma R, et al. Prevalence of cleft lip/palate in the Fangshan district of Beijing, 2006-2012. The Cleft Palate-Craniofacial Journal 2018;55:105566561876711:1296-301.

10 Michael Dixon;, Marazita J.;, Mary; L. Cleft lip and palate: understanding genetic and environmental influences, 2011.

11 Committee GhaH, ed. Notice on Promoting Comprehensive Prevention and Control of Birth Defects in Guangdong Province, 2015.

12 CPPCC Mot, ed. China's total quality medical and health resources are insufficient and unevenly distributed, 2011.

13 Si C, Feng C, Xiuting L. Guangdong first provincial health conference, 2017.

14 IPDTOC Working Group. Prevalence at birth of cleft lip with or without cleft palate: data from the International perinatal database of typical oral clefts (IPDTOC). Cleft Palate Craniofac J 2011;48:66-81. 
15 Moreau JL, Caccamese JF, Coletti DP, et al. Tissue engineering solutions for cleft palates. J Oral Maxillofac Surg 2007;65:2503-11.

16 Leslie EJ, Marazita ML. Genetics of cleft lip and cleft palate. Am J Med Genet C Semin Med Genet 2013;163C:246-58.

17 Allori AC, Mulliken JB, Meara JG. Classification of cleft lip/palate: then and now, 2017: 175-88.

18 Koul R. Describing cleft lip and palate using a new expression system. Cleft Palate Craniofac J 2007;44:585-9.

19 Marazita ML, Mooney MP. Current concepts in the embryology and genetics of cleft lip and cleft palate. Clin Plast Surg 2004;31:125-40.

20 Martín-Del-Campo M, Rosales-lbañez R, Rojo L. Biomaterials for cleft lip and palate regeneration. Int J Mol Sci 2019;20. doi:10.3390/ ijms20092176. [Epub ahead of print: 02 May 2019].

21 Cooper ME, Ratay JS, Marazita ML. Asian oral-facial cleft birth prevalence. Cleft Palate Craniofac J 2006;43:580-9.

22 Lee CW, Hwang SM, Lee YS, et al. Prevalence of orofacial clefts in Korean live births. Obstet Gynecol Sci 2015;58:196-202.

23 Fleurke-Rozema JH, van de Kamp K, Bakker MK, et al. Prevalence, diagnosis and outcome of cleft lip with or without cleft palate in the Netherlands. Ultrasound Obstet Gynecol 2016;48:458-63.

24 Sarmiento K, Valencia S, Gracia G, et al. Clinical and epidemiologic description of orofacial clefts in Bogota and Cali, Colombia, 20012015. Cleft Palate Craniofac J 2018;55:517-20.

25 Alonso RRH, Brigetty GPS. Analysis of the prevalence and incidence of cleft lip and palate in Colombia. Cleft Palate Craniofac $J$ 2020;57:552-9.

26 Medeiros AN, Virgínio FT, Sousa COED. Prevalence of cleft lip and palate in Brazilian children 2011 - 2015. IJMU 2018;13. doi:10.4314/ ijmu.v13i1.3

27 Wang M, Meng R, Wang Z, et al. Prevalence of oral clefts among live births in Gansu Province, China. Int J Environ Res Public Health 2018;15:380. doi:10.3390/ijerph15020380

28 Chincharadze S, Vadachkoria Z, McHedlishvili I. Prevalence of cleft lip and palate in Georgia. Georgian medical news, 2017: 24-8.
29 Jahanbin A, Eslami N. Seasonal and yearly trends in cleft lip and palate in northeast Iran, 1989-2011. J Craniofac Surg 2012;23:e456-9.

30 Chang W-J, See L-C, Lo L-J. Time trend of incidence rates of cleft lip/palate in Taiwan from 1994 to 2013. Biomed J 2016;39:150-4.

31 Abreu MHNG, Lee KH, Luquetti DV, et al. Temporal trend in the reported birth prevalence of cleft lip and/or cleft palate in Brazil, 2000 to 2013. Birth Defects Res A Clin Mol Teratol 2016;106:789-92.

32 Chen J, Huang X, Wang B, et al. Epidemiology of birth defects based on surveillance data from 2011-2015 in Guangxi, China: comparison across five major ethnic groups. BMC Public Health 2018;18:1008.

33 Xie D, Yang T, Liu Z, et al. Epidemiology of birth defects based on a birth defect surveillance system from 2005 to 2014 in Hunan Province, China. PLoS One 2016;11:e0147280.

34 Hermann NV, Darvann TA, Munch A et al. Parental age in relation to the severity of cleft lip and/or palate. Orthod Craniofac Res 2018;21:236-41

35 Urbanova W, Kotova M, Vankova Z. The incidence of cleft lip and palate in the Czech Republic in 1994-2008. Bratis/ Lek Listy 2013;114:474-9.

36 Bellis TH, Wohlgemuth $\mathrm{B}$. The incidence of cleft lip and palate deformities in the south-east of Scotland (1971-1990). Br J Orthod 1999;26:121-5

37 Wilson J, Hodges A. Cleft lip and palate surgery carried out by one team in Uganda: where have all the palates gone? Cleft Palate Craniofac J 2012;49:299-304.

38 Stoll C, Alembik Y, Dott B, et al. Epidemiological and genetic study in 207 cases of oral clefts in Alsace, north-eastern France. J Med Genet 1991:28:325-9.

39 Milan M, Astolfi G, Volpato S, et al. 766 cases of oral cleft in Italy. data from Emilia Romagna (IMER) and northeast Italy (Nei) registers. Eur J Epidemiol 1994;10:317-24.

40 Croen LA, Shaw GM, Wasserman CR, et al. Racial and ethnic variations in the prevalence of orofacial clefts in California, 19831992. Am J Med Genet 1998;79:42-7. 